una inocencia naturats. Ln clla se dan relaciones do opresion sexual, explotación laboral, discriminacion étnica, etcétera.
Tara una introducción a esta particular y compleja problemática tience especial interés algunos tra. bajos de P. Rodenas (1921 y 1994).

\title{
Isonomía, Isegoría, Isomoiría * y democracia a escala global
}

\author{
PHILIP RESNICK \\ Universidad de British Columbia
}

\begin{abstract}
Desde la antigüedad hasta nuestros dias, virtualmente todos los defensores a ultranza de la democracia y del gobierno republicano han subrayado de manera enfática cómo las desigualdades económicas amenazan la democracia.
\end{abstract}

Robert Dahl

Uno de los procesos más sorprendentes de finales del siglo $\mathrm{xx}$ es la tendencia hacia la globalización de la democracia. En Latinoamérica, la transición de autoritarismo a democracia dominó la política durante la década de los ochenta y trajo consigo la restauración de regimenes democráticos a lo largo de todo el cono sur, así como una mayor democratización de la vida política en Centroamérica y México ${ }^{2}$. Desde 1985, con la ascensión de Mijail Gorbachov a la posición de Secretario General del Partido Comunista de la Unión Soviética, los términos glasnost y perestroika se convirtieron en los emblemas de una fase nucva, más democrática, en la Unión Soviética y, por añadidura, cn toda Europa del Este ${ }^{3}$. El modelo marxista-leninista de partido de vanguardia y de sistema de partido-Estado contralizado, comenzó a dejar paso a algo substancialmente más abierto, pluralista y descentralizado en la Unión Soviética misma, en donde se producía una creciente separación entre el Estado y el partido, el centro y las repúblicas de la unión, la sociedad civil y el estado, que se acabarian por convertir en norma. Desde Polonia hasta Bulgaria se producía, a finales de la década de los ochenta, un accleramiento de la historia con el hundimicnto de la mañana a la noche del modelo marxista-leninista. La victoria del movimiento Solidaridad en Polonia, la caída del muro de Berlin y la subsecuente unificacion de las dos Alemanias, la Revolución de Terciopelo checoslovaca, la adhesión de Hungría a la economía de mercado, el violento derrocamiento de Ceaucescu, la sígnificativa erosión del apoyo al comunismo en Bulgaria, Yugoslavia y (ironía de ironías) en la estalinista Albania, todo esto significaba el comienzo de un nuevo capítulo en esa parte del mundo.

Tanto en el sureste asiático como en el sur de Asia se han producido avances, aunque frágiles, hacia la democratizacion: en países como Corea del Sur, Taiwan y Filipinas, así como en Pakistán, Nepal y Bangladesh. Si bien estos avances hacia la democracia se han visto acompañados,

\footnotetext{
* Iraducción de Elvira Bartoso. Una primera versión del presente trabajo fue publicada por Paxis Intemational.
} 
ciertamente, de dramálicos retrocesos como por ejemplo en China, Birmania (hoy Myanmar) y, más recientemente, Tailandia. Sin embargo, el ímpctu hacia la democratización está bastante vivo cn lo que va de década. También on África, países de la importancia de Nigeria y Sudáfrica han experimentado la democratización en los últimos años, y el modclo de partido único ha desaparecido en Mozambique, Angola, el Congo y Etiopía, por poner sólo cuatro ejemplos. Hemos de intervenir entre estas transformaciones, tanto en términos de las fuerzas mayores (económicas, ideológicas, culturales) que operan en nuestro mundo de finales del siglo $x x$, como a la luz de las lecciones negativas que nos han enseñado los estados de seguridad nacional de Latinoamérica y los regímenes marxista-leninistas *

Estos cambios no se han producido en el vacío. Como minimo, las últimas dos o tres décadas han sido testigos del surgimiento de una división internacional nueva del trabajo, más global en carácter que cualquicra de las anteriores. Las corporaciones multinacionales y los bancos llevan a cabo sus actividades de continente a continente. Incluso cn los gustos de los consumidores y en las formas culturales del capitalismo avanzado, se pueden observar paralelismos significatives desde Tokyo, pasando por Paris, hasta San Francisco. La tecnología de la información, la televisión y las películas, en particular, han traído los estilos de vida de Occidente, con su consumo de masas y sus imágenes de abundancia, a las pantallas del segundo y el tercer mundo, y durante este proceso han contribuido at crear una opinión pública más recepliva a los modelos económicos y politicos de Occidente. Asimismo, las fallas evidentes de la economía centralizada, planificada, del lipo soviético o la supresión de libertades elementales bajo los regímenes autoritarios (tanto de derechas como de izquierdas), han contribuido a crear los elementos, entre intelectuales, estudiantes, miembros de la clase media y de la clase trabajadora y del campesimado, para la constitución de algo más claramente democrático.

Existe, sin embargo, una gran ambigüedad en torno a términos como democracia mundial y a las implicaciones de las transformaciones que cstamos observando. Para muchos de los que ocupan las posiciones de poder en las sociedades occidentales, $y$, por consiguiente, en las socicdades democratizadas recientemente, la democracia es de tipo multipartidista, en donde se convocan elecciones nacionales de manera regular. Las legislaturas nacionales tendrán representación dc los partidos políticos mayoritarios; la rama ejecutiva del gobierno tendrá suficicnte área de maniobra entre elecciones, un cuerpo burocrático de cierto tamaño; el poder militar estará subordinado al poder cjecutivo; el judicial será independiente: la prensa será libre, etc. Los actores económicos, en su mayor parte, serán independientes de los políticos, con principios de mercado propios en los que sólo de manera modesta intenvendrá el gobierno, haciendo balance, suministrando los soportes para una sociedad libre ${ }^{5}$. Este es el modelo que otras (menos afortunadas) sociedades han de imitar, si se pretende que este mundo sea seguro para la democracia.

Bajo el triuntalismo de los líderes occidentales y los portavoces de los medios de comunicación, que glorifican la victoria de «nuestro* sistema sobre sus rivales, yace, curiosamente, un asunto inacabado. No hace mucho tiempo los mismos lideres de opinión se lamentaban de la "crisis de la democracia» originada por la sobrecarga del sistema político a través de las demandas que emanan de los cstudiantes, los activistas negros, etc ${ }^{5}$. Tampoco se han mostrado receptivos los archidefensores de los principios del mercado en las pasadas décadas, hacia las dimensiones comunitarias e 
igualitarias de la democracia; cuestiones que han puesto sobre el tapete los adhesores a los movimientos ciudadanos, ecologistas o feministas. Ciertamente, no está claro que, si se vicran obligados a elegir entre los polos abiertamente capitalista o abiertamente democrático de la sociedad contemporánca, Milton Friedman, Friedrich Hayek y James Buchanan no acabarían cscogiendo el primero ?. Los criticos liberales de la democracia en el siglo XIX solian criticar sus excesos igualitarios ${ }^{8}$, y éste parece ser también el leitmotif de los críticos neo-conservadores del gasto social, la intervención estatal y la irresponsabilidad fiscal.

Por otra parte, mucho del criticismo que ha surgido en Occidente acerca del excesivo poder de que gozan las grandes corporaciones, acerca de la concentración de los medios de comunicación o acerca de la influencia del dinero en la competencia electoral y el sistema de partidos, ha sido sugerido en nombre de la democracia. Desde C. Wright Mills, con su critica del poder elitista de mediados de los cincuenta en los Estados Unidos ${ }^{9}$, pasando por los teóricos de la democracia participativa de la década de los sesenta ${ }^{10}$, hasta las llamadas recientes al control comunitario de los depósitos de residuos tóxicos nucleares, o a conceder parcelas de poder a las poblaciones aborígenes, las mujeres, las minorias étnicas y de otros tipos, el principio racional que subyace parece ser el mismo. La política del tipo jerárquico, tal y como la vivimos en las sociedades occidentales ( 0 no occidentales) es demasiado excluyente, demasiado carente de respuestas a las necesidades y demandas (ya sean éstas económicas, culturales o políticas), como para merecer el título de «democrática», en el sentido de «gobierno del pueblo». Nuestros sistemas políticos, podría sostenerse, son sistemas que están regulados cada vez más por la lógica de un capitalismo global con elementos liberales y principios repre- sentativos a modo de hojas de parra, con los que cubre su desnudez moral y política.

Uno no está obligado a abandonar la democracia liberal total o parcialmente, ni a negar sus méritos (superiores, sin duda, si se comparan con el resto de modelos de que se dispone en el siglo $\mathrm{XX}$, desde el fascismo hasta el estalinismo), para reconocer cierta verdad en este criticismo. La relación entre liberalismo y democracia ha sido siempre problemática, como Norberto Bobbio nos recuerda:

«El liberahismo amputa el individuo del cuerpo orgánico [...], la democracia los vuelve a unir una vez más, junto a otros iguales a él. El liberalismo subraya la capacidad de autocreación del individuo [...] en condiciones de libertad máxima de toda constricción impuesta externa o coercitivamente; la democracia ticne en la más alta estima la capacidad del individuo para superar el aislamiento al [...] permitir la instauración de un poder común benéyolow ".

Además (como el liberal francés Benjamin Constant subrayó al principio del siglo XIX), existía una contrapartida signifícativa entre los derechos de los ciudadanos que participaban en la toma de decisiones colectiva de la polis o la res pública de la antigüedad, y las libertades individuales y derechos que en comparación son dominantes en los tiempos modernos ${ }^{12}$. Existen, y deben de existir, ciertas dudas acerca del alcance de nuestros logros democráticos, cuando pensamos en otros modelos más participativos del pasado o cuando, al quitarnos nuestras anteojeras ideológicas, contemplamos la desigualdad de condiciones $y$, por consiguiente, de poder, que el capitalismo, debido a su propia naturaleza, engendra.

Para explorar un poco más algunas de las tensiones del discurso democrático contemporáneo entre los modelos representativo y participatorio, entre los principios de libertad e igualdad, entre las esferas 
políticas y económicas, permítanme sugerir una breve vuelta a los gricgos. Como inventores de la democracia, por decirlo de algún modo, y de las categorias asociadas a ella, los griegos de los siglos vi y rV a.C., aún tienen cierta influencia en nucstro propio mundo. A pesar de las deficiencias de la democracia ateniense con respecto a los esclavos, y a la exclusión de las mujcres y los extranjeros de la categoría de ciudadania, sigue siendo el prototipo para mucha de la experimentación democrática que se ha venido produciendo desde entonces.

El término demokratia, sorprendentemente, no cra el término crucial que se empleaba durantc los siglos v y vi, cuando se hacía referencia al gobierno de muchos ${ }^{13}$. El término cmpleado más frecuentemente era, de hecho, cl de isonomia ${ }^{14}$, que hacia referencia a la igualdad de todos los ciudadanos atenienses ante la ley. La igualdad de derechos do ciudadanía podría contrastarse con la situación de las aristocracias y las monarquías, en donde uno o unos pocos posecn privilegios que se les niega a los demás. Como consecuencia de las reformas de Clístenes en el 510 a.C. y de las Guerras Persas, Atenas introdujo el más básico y elemental de los preceptos.

Un segundo término empleado en el siglo $\vee$ a.C. como sinónimo de democracia se derivó también de la raíz griega ison, 0 igual. Es el têrmino de isegoria ${ }^{15}$, que hace referencia al derecho de los ciudadanos atenienses a formar parte de las reuniones de la asamblea $y$, por consiguiente, a hablary votar en materias que conciernen a la polis. Este término captura el elemento de participación en la democracia ateniense, el cual, por supuesto, era mucho más importante de lo que hoy en dia es en las formas más indirectas de democracia.

Hay un tercer término, isomoina, que se refiere a la división igual de la tierra, y que puede ser interpretado como la demanda del elemento más radical de la población de Atenas y de la Ática ${ }^{16}$. Encontramos el término en un poema de Solón al principio del siglo $\mathrm{Vl}$, donde el legendario legislador se enorgullece de que aun cuando habia cancelado las hipotecas (de los campesinos), no cedió ante las demandas de quienes reclamaban igual división de la tierra ${ }^{17}$. Si bien el término parece no haber sido utilizado con demasiada frecuencia durante $\operatorname{los} \operatorname{siglos} \mathrm{V} y$ IV a.C, hace referencia a las demandas de formas de democracia económicas, además de políticas. $Y$ es este sentido más igualitario, en lo que concierne a la propiedad, 1o que ha debido hacer que Aristoteles, cn un célcbre parágrafo de su Política, definiera la democracia no tanto como el gobicrno de muchos, sino como el gobierno de los pobres ${ }^{18}$.

Lo que quicro sostener en este ensayo es que estos tres términos gricgos, nominalmente, isonomia, isegoria e isomoiria, tienen un espacio en una teoría democrática contemporánea, especialmente, en una que pretenda tener cierto atractivo universal. No estoy convencido de que cualquiera de ellos preceda absolutamente a los otros dos, sino que, por el contrario, querría sostener la necesidad de un equilibrio razonable entrc los tres.

Isonomia puede parecer el más inequívoco de estos términos, si bien ha sufrido la tendencia a ser el precepto democrático más violado en los regímenes de tipo autoritario o de partido único. La igualdad formal de los ciudadanos ante la ley y un gran paquete de derechos no significan nada en una sociedad de torturadores y policía secreta, una prensa y una vida intelectual amordazadas, un proceso político jerarquizado, centralizado y totalmente controlado. La libertad de expresión, de reunión, de conciencia no son libertades puramente formales que distrazan la realidad de la dominación burguesa y del capitalismo monopolista, como la ideología marxis- 
ta-leninista quería que creyéramos. ¿Quién puede leer pasajes como el siguiente de la era Brezhnev, ensalzando el carácter democrático del socialismo real, sin partirse de risa?

«El sistema socialista posee un criterio completamente nuevo para juzgar la democracia; criterio que es desconocido para toda sociedad cxplotadora [...]. La participación de cada ciudadano en la administración de asuntos comunes es la esencia del concepto marxista-leninista de democracia [...]. Los ciudadanos soviéticos tienen garantizadas la libertad de cxpresión, de prensa, de asamblea [...]. Tienen el derecho de asociarse en organizaciones públicas, el derecho a la libertad de conciencia [...] a la inviolabilidad de la persona y el hogar, a la privacidad de su correspondencia, conversaciones telefónicas y comunicaciones telegráficas" ${ }^{19}$.

El culto a la personalidad en muchos regimenes marxista-leninistas, la existencia de un estrato privilegiado de autoridades o nomenklatura, la marginalización, encarcelación o supresión de los disidentes politicos y la omnipresencia del partido, se dirigían a una sociedad en donde la isonomia era una palabra vacia. Como Tatyana Zaslavscaya, la socióloga soviética más eminente de nuestros días, observa:

"La totalidad de la vida social estaba impregnada de hipocresía [...]. La sociedad soviética estaba caracterizada por la excepcionalmente desigual distribución del poder político y un nivel extremadamente bajo de participación en el gobieno por parte de las masas trabajadoras [...]. La administración de la arena cultural era tan burocrática como la administración de la economia. Las casas cditoriales más poderosas entendían que su meta en esta vida consistía en dejar de editar todo to que fuera inusual, colorido, animado. El pensamiento libre y sin prejuicios levanfaba la indignación de los editores» ${ }^{20}$.
Del mismo modo, en las sociedades fascistas de los años veinte y treinta y en sus ramificaciones latinoamericanas o asiáticas tras la Segunda Guerra Mundial, apenas quedaba espacio para los dercchos de los ciudadanos. Ciertos individuos y grupos eran prima facie designados como enemigos del pueblo (comunistas, socialistas, sindicalistas, intelectuales independientes, judios, «subversivos», lo que fuera), y se les privaba de todo estatuto civico. Los más altos intereses de Estado, cl Reich, la doctrina de la seguridad nacional, prevalecian sobre cualquier precocupación escrupulosa acerca de los derechos, los cuales, a su vez, eran producto del degenerado credo democrático liberal. Los lideres fascistas, los caudillos militares y gobcrnadores oligarcas, se situaban más allá de cualquier sanción constitucional y, como los tiranos de la antigüedad, habían convertido el Estado en un propio dominio personal.

La experiencia del siglo $\mathrm{xx}$ nos enseña, una vez más, los grandes peligros del poder tiránico. Es una lección que los teóricos democráticos de los siglos iv y $\vee$ habían digerido ya, y que subyace a la introducción de la democracia a consecuencia del derrocamiento de las tiranias de Pisístrato y sus hijos Hypias e Hiparco ${ }^{21}$. Ninguna ciudadanía puede proclamarse libre o ejercer verdadero poder si una persona o un grupo se apropia de todo el poder. La isonomia vino a significar cl control de los ciudadanos sobre las cortes de ley y los consejos, las asambleas y todas las oficinas cívicas de Atenas. Gobernar en nombre del pueblo, como todo tirano pretende hacer, no era sustituto posible al gobierno del pueblo 22 .

Implicitamente, la isonomia engendra también la necesidad de cierto grado efectivo de participación ciudadana. La isego. ría, el segundo de nuestros términos griegos, habla de esta dímensión participativa, bastante más presente en la antigua sociedad de Atenas que en la de nuestros dias. 
Los rasgos participativos de la polis ateniense ( 500 miembros rotativos anualmentc en el bulè, o consejo, elegidos al azar; 30-40 reuniones anuales de la ekklesia, o asamblea popular, en la que todos los ciudadanos atenienses podian formar parte; un gran número de cargos judiciales y cívicos que se cubrían al azar) han sido ampliamente discutidos en la literatura ${ }^{23}$. No necesitamos idealizar los logros do la isegoria ateniense pretendiendo que la mayoría de los ciudadanos se aprovechara del derecho de atender cada reunión de la asamblea (aun cuando se pagara por atenderlas dos óbolos, desde finales del siglo ven adelante), y mucho menos de que participaran o intervinieran en los debates. $\mathrm{Ni}$ debemos entusiasmarnos con el modelo ateniense de democracia por encima de nuestro propio modelo, rebajando así la importancia de las serias restricciones que existian para acceder a la categoría de ciudadano o ignorando las tan diferentes condiciones de vida en las ciudades-Estado, en comparación con las naciones Estados en que vivimos.

Sin embargo, he de confesar el atractivo irresistible, a pesar de sus muchas limitaciones, que la democracia atenicnse tiene para quienes han de ser los teóricos de la democracia de finales del siglo $\mathrm{Xx}$. Es como si su misma inmediatez, todo lo contrario a nuestro modelo indirecto, nos importunara en nuestra conciencia colectiva; como si sus presuposiciones normativas acerca de la virtud cívica nos aguzara en nuestras preocupaciones modernas (más privativas); y su misma frescura se alzara como un reproche a la realidad más cínica y hastiada de la política democrática liberal. Como Marx observaba en otro contexto: «iPor qué no habría de ejercer la infancia de la sociedad humana, en donde habia obtenido su desarrollo más hermoso, un encanto eterno como una edad que nunca habrá de volver?» ${ }^{24}$.
Un gran número de teóricos (desde James Madison a los adhesores al modelo competitivo de élite del siglo $\mathrm{XX}$ ) nos han contado, por supuesto, que la democracia ateniense es, en el mejor de los casos, una imposibilidad y, en el peor, una dystopia incompatible con las complejidades de las sociedades modernas, los imperativos de la estabilidad gubernamental o las verdades de la naturaleza humana ${ }^{25}$. Además, no se puede negar ni la existencia de una división laboral evidente entre gobernantes y gobernados en toda sociedad a gran escala, ni el interés esporádico (en el mejor de los casos) que los ciudadanos corrientes demuestran hacia la participación política en los largos intervalos que hay entre elecciones. Los teóricos politicos pueden esbozar sus modelos de democracia participativa, democracia a nivel de base, tele-democracia, democracia unitaria, democracia económica, hasta sus últimas consecuencias: la energética isegoria aparece como un retroceso hacia un pasado irrecuperable.

Pero blo es realmente? En ciertos aspectos, la isegoria está verdaderamente viva cn las socicdades contemporáneas. Un ejemplo obvio es el referéndum, ya sea en materia constitucional (Australia, Francia), como en cuestiones de soberanía (Reino Unido, Irlanda, Dinamarca y Noruega, al considerar la integración en la Comunidad Económica Europea), como en los acuerdos federales (Quebec, Eslovenia, Croacia, las repúblicas Bâlticas), y en toda una gama de cuestiones políticas y sociales (Italia, Suiza, algunos estados de los USA). Aunque son los gobiernos quienes a menudo inician las consultas mediante referéndum, no siempre es éste el caso $^{26}$. Además, si bien están ciertamente sujetos al maluso y al abuso (el ejemplo do California viene a la mente), parece un instrumento particularmente apropiado para decidir las cuestiones más importantes de la política nacional, las cuales reper- 
cutirán a largo plazo en la sociedad (cuestiones constitucionales, cuestiones de soberamia, etc.).

Más allá del referendum existe otra esféra de actividad política a nivel local o subnacional (pero también a nivel nacional) que invita a la participación directa. Las formas más dramáticas que ésla puede adoptar son los momentos de protesta o desobediencia civil del tipo que agitó las sociedades occidentales en los años sesenta (Japón, Francia, Alemania Occidental y los Estados Unidos); o amplios movimientos populares que han ayudado a iniciar la transición de regímenes autoritarios a regímenes de tipo más democrático en Latinoamérica (Brasil en 1984; Chile), África (Argelia y Tunicia), Europa del Este (Polonia, Alemania Oriental, Checoslovaquia, Rumania, Albania, varias repúblicas Bálticas), y Asia (Corea del Sur, Filipinas, Bangladesh). Si bien los movimientos de radicalización y movilización popular son, por definición, temporales, pueden llegar a tener un impacto positivo y duradero en el desarrollo democrático de una nación.

No menos relevantes son los movimientos sociales que representan la auto-organización de la sociedad con miras a la democratización de grandes áreas de la vida cotidiana, económica o social. Uno piensa en los movimientos de los campesinos en varias partes del tercer mundo, en los rccién formados sindicatos en socicdades que experimentan una rápida industrialización (Corea del Sur o Brasil entre finales de la década de los setenta y principios de la de los ochenta). Uno piensa en el feminismo y, más generalmente, en el movimiento de mujeres, con su reto a las relaciones de género cxistentes, las políticas sociales y el límite mismo entre los dominios de lo público y lo privado ${ }^{27}$. El ecologismo (un movimiento cada vez más global en carácter) tambiến viene a la mente, con su insistencia en el control local, comunal o indígena de los recursos, y que entiende el desarrollo como una cuestión de conservación y sostenimiento a largo plazo, en vez de creer en el ethos del crecimiento y del beneficio de un capitalismo transnacional, altamente concentrado y en absoluto democrático ${ }^{28}$. Del mismo modo funcionan varios movimientos por los derechos humanos: desde Las Madres de la Plaza de Mayo en Argentina, pasando por Charter 77 y Foro Cívico en Checoslovaquia, hasta los estudiantes disidentes en la plaza de Tiananmen en la primavera de 1989, por citar sólo tres ejemplos de lucha por la democratización en varias partes del mundo.

Reducir la democracia a una serie de arreglos de procedimiento en los que tienen que ver las preferencias de representantes electos y cargos oficiales, a quienes se delega el poder de tomar decisiones cada cuatro, cinco o seis años, es una renuncia muy seria de la capacidad de participación. Es ignorar las luchas que hubieron de librarse para alcanzar la democracia, desde aquellos que cxtendieron los privilegios en Gran Bretaña, pasando por los movimientos abolicionistas y de derechos civiles en los Estados Unidos, hasta las varias revoluciones en Francia desde 1789 en adelante (así como en otras partes del mundo). Es iluminar el hecho de que la democracia (como Pericles, por citar un ejemplo, perfectamente entendió), implica el interés constante y el compromiso de toda la ciudadanía en su conjunto ${ }^{25}$. Una política sin isegoría es una política en donde el demos habla con una voz muda.

Al afirmar esto, sin embargo, soy también consciente del peligro que supone llevar el impulso participatorio demasiado lejos. No tenemos elección en nuestras sociedades densamente pobladas, con su gran división laboral y su base territorial extensa sino la de aceptar el principio representativo como la expresión principal de la política democrática. No podemos recrear sociedades a pequeña escala como 
las que apuntó Rousseau, por ejemplo, aunque podemos, puntual y localmente, ser capaces de introducir una política más directa a nivel local o de la comunidad. No hay modo, sin embargo, de darle vuelta a la página, retrocediendo hasta cierto estadio de desarrollo anterior a la nación-Estado; el camino hacia una democracia más global implicará, si acaso, una extensión mayor del principio representativo en instituciones a nivel planetario.

Además, como Bobbio destacó, existe una tensión entre los polos liberal y democrático en teoria democrática liberal. En e] discurso filosófico contemporáneo de Occidente, esto se refleja en los debates entre liberales y comunitaristas acerca de la posición que deben ocupar los derechos y la relativa importancia de las dimensiones individual y colectiva del comportamiento político ${ }^{30}$. Invocat los términos de isonomía e isegoria, una vez más, puede permitirnos rastrear la genealogía de esta división.

Si uno interpreta la isonomía como igualdad de derechos ante la ley, entonces uno está justificado parcialmente en dar a esos derechos (por ejemplo, el derecho a un juicio justo o a la libertad de expresión) un cierto tono individualista. Estos no eran, por supuesto, derechos que pudieran ser ejercitados de algún modo fuera de la comunidad de la polis, ni yo estoy sosteniendo que los griegos compartieran totalmente nuestra moderna noción de libertad individual ${ }^{31}$. La isonomia, por lo menos, no cierra la puerta a tal concepción. La isegoría, por el contrario, posee un tono más colectivista con su énfasis en la participación en las deliberaciones de la asamblea. Es el medio por el cual el demos, la ciudadanía congregada colectivamente, por dccirlo de algún modo, ejercita el poder. Mientras que el choque de opinio. nes es una partc inherente del proceso de deliberación, el resultado final son edictos o decretos que atan colectivamente y que no permiten el disenso individual.

En su acepción moderna, la isegoría (particularmente en los períodos revolucionarios como, por ejemplo, en la fase Jacobina de la Revolución Francesa, la fase Bolchevique de la Revolución Rusa o la Revolución Cultural China de mediados de los sesenta) puede conducir a una versión de la participación extremadamente antiliberal. Los disidentes de la línea oficial reciben el sello de traidores o contra-revolucionarios; las libertades para esos miembros de la sociedad van desapareciendo, y más adelante comienzan a desaparecer para todo el mundo ${ }^{32}$. Igualmente, la participación en grandes convocatorias al estilo de la de Nüremberg durante el período culminante del régimen Nazi, tiene poco que ver con la democracia tal y como la entendemos. El propósito de mis ejemplos no es denigrar el concepto de participación, al que defendí en un pasaje anterior; sino, simplemente, reconocer la necesidad de hacer un balance en teoría de la democracia, entre la isegoría y las libertades más formales a las que se refiere la isonomía (tal y como podríamos interpretarlas para nuestra propia época). No sólo es una imposibilidad la participación de todos los ciudadanos en los asuntos políticos de manera continua, sino que la participación en masa, cuando es orquestada desde la cúspide o forzada mediante la coerción (física o ideológica) a gran escala, pucde adquirir un tono radicalmente anti-democrático. Esto, ciertamente, nos ha enseñado la pseudo-participación en los regímenes autoritarios del siglo $\mathrm{XX}$.

Esto me conduce al tercero de nuestros términos griegos, isomoiria, para hablar de las dimensiones economicas de la democracia. Ésta es la dimensión de la que, mâs obviamente, se carece en Asia o Latinoamérica hoy en día, y que, hasta ahora, ha sido menos articulada desde Occidente, 
a pesar de la llegada del Estado de bienestar.

Como se puede observar en las estadísticas al uso, la distribución de la renta en el tercer mundo sigue siendo bastanto más desigual que cn el mundo desarro. llado. Este, por su parte, tiene problemas fundamentales en el acceso a la educación, a servicios destinados a cuidar la salud, a bienes económicos básicos y al sistema político mismo.

¿Podemos hablar de igualdad de oportunidades o de opinión cuando las diferencias de clase y de status están tan profundamente entretejidas? Sin una medición constante de los niveles de bienestar o de las redistribuciones mínimas de la riqueza a través del sistema de tributario, que provea una red de protección para todo el mundo, zpueden las políticas, tanto del norte como del sur, decir que han establecido las condiciones necesarias para la política democrática?

Por lo que sabemos, Atcnas en los siglos V y IV a.C., no cumplía con el principio de isomoiria del mismo modo en que cumplía la isononia y la isegoria. Existían diferencias reales de riqueza y renta cntre los ciudadanos, posiblemente tan grandes como en las democracias liberales occidentales de nuestros días ${ }^{33}$. Lo que es cierto, sin embargo, es que Atenas, a través de recursos como el de pagar a quien asistiera a las asambleas (o medidas como la propuesta por Demóstenes cn el 348 a.C., de proveer un estipendo regular a cada ciudadano ateniense, para que pudiera realizar cualquier tarea del Estado para la cual estuvicra mejor preparado) ${ }^{34}$, pudo mantener viva una dimensión más igualitaria de la ciudadanía. Además, cl poder político podía ser movilizado (para cscándalo do los críticos aristocráticos de la democracia como, por ejemplo, Platón) para erosionar las, profundamente enraizadas, diferencias de clase y status.
Un rasgo clave de la democracia ateniense era el uso del poder político por parte de sus usufructuarios para equilibrar las desigualdades sociales, especialmente, la distribución desigual de la riqueza ${ }^{35}$.

En el mundo moderno, éste parece ser que era el objetivo del movimiento hacia una noción más positiva del estado entre los pensadores liberales de finales del siglo XIX, así como del ímpetu hacia el gasto social y las soluciones keynesianas en politica macroeconómica desde la década de los treinta. Ciertamente, el consenso en el estado de bienestar keynesiano de los años sesenta, desde el punto de vista de escritores como Andrew Shonfield, equilibraba el poder económico del capital privado y del mercado, con el poder político del estado sobre el que sindicatos y partidos de izquierda o liberales o cristiano-demócratas tenían una gran influencia ${ }^{3 /}$. Un elemento de la isomoiría funcionaba en las sociedades occidentales, a través de las empresas del estado $\mathrm{y}$, más significativamente aún, a través de los mecanismos distributivos de un sistema tributario progresista.

El consenso keynesiano de los años de posguerra había de dejar paso a la stagflation * ${ }^{37}$ de la década de los setenta, y a un retorno a las filosofias públicas más anti-igualitarias y más orientadas hacia el mercado, asociadas con la mueva derecha. En el fondo del neo-conservatismo, ya sea en Gran Bretaña, los Estados Unidos de América o en otras sociedades democráticas liberales, yace un rechazo a la isomoiria y a sus efectos, supuestamente debilitantes, tanto para la libertad de las empresas como para la individual ${ }^{38}$.

En las sociedades que avanzan desde el autoritarismo a la democracia, como por ejemplo España y Portugal en la década de los setenta, o ciertos países de Latinoamérica en la de los ochenta, la cuestión acerca de la isomoinia se ha entendido desde una perspectiva diferente. Aun cuando 
profundas divisiones de clase del tipo capitalista o precapitalista existian, el problema de una transición exitosa consistía, en una gran parte, en separar la cuestión de la redistribución económica de la, no menos espinosa, cuestión de la norma constitucional. Era crucial, para los partidos del centro y de la izquierda, ascgurar a los intereses económicos dominantes dentro de sus sociedades, que esos intercses no se verían amenazados en un régimen menos autoritario que el de Franco o el de los militares latinoamericanos. Como Santiago Carrillo, lider del Partido Comunista de España, lo expuso: «Uno ha de tener el coraje de explicarle a la clase trabajadora que es mejor darle a la burguesía su plusvalía, en lugar de crear una situación que contenga el riesgo de volverse contra nosotrosm ${ }^{39}$. Sindicatos y grupos populares han de acallar sus demandas de isomoiria para poder asegurar cierta isonomia e isegoria. El que vayan o no a ser capaces de poner en su agenda, en un período post-transicional, la reinvindicación de la isomoira y de qué manera, determinará el ulterior ćxito o fracaso de sus gobiernos, para satisfacer las necesidades económicas y sociales más elementales de la mayoría de la población.

En Europa del Este, la isomatía se encontraba en el centro mismo de la idcología marxista-leninista y en sus pretensiones de estar poniendo en funcionamiento la verdadera democracia, en oposición a la democracia fraudulenta, clasista de Occidentc. Si bien en ciertos aspectos había más igualdad en las sociedades marxistas-lcninistas entre trabajadores no cualificados y los profesionales ${ }^{40}$, tal igualdad implicaba un coste altisimo. No sólo eran inaccesibles los privilegios de los defensores del régimen para otros miembros de la socicdad, sino que también había una ausencia general de libertades para todos $y$, en último término, el nivel de funcionamiento cconómico (y ecológico) puso a cstas sociedades años atrás de los niveles atcanzados por las economías mixtas capitalistas. No es sorprendente, a corto plazo al menos, que la prioridad más acuciante consista en el desarrollo de más economias de mercado, y en el consolidamiento de libertades formales que asociamos con el término de isonomía. A medio y largo plazo, sin embargo, se puede sostener que algunas de las razones que condujeron al desarrollo de redes sociales e intervención estatal en Occidente (nominalmente, la rampante desigualdad engendrada por un capitalismo no regulado), entrarán en funcionamiento en Europa del Este tambien. Cuando esto ocurra (y puede que ya esté ocurriendo), la isomoinía será rescatada del maluso al que fue sometida por parte de la ideologia marxista-leninista para justificar la versión autoritaria del socialismo de estado.

Mi propia opinión ( $y$ no esconderé aquí prejuicios de centro-izquierda) es que la isomoiria necesita constituir una parte integral de toda teoría democrática que merezca ese nombre. No necesita, ni detre, converlirse en una preocupacion tan abrumante que amenace la existencia misma de la isonomia y de la isegoria. Pero, al mismo tiempo, la igualdad formal de todos ante la ley no debería servir como impedimento para la introducción de grados de desigualdad social y política significativamente menores que los que prevalecen en la actualidad. La cuestión de una distribución más justa de la tierra, un acceso más justo a la educación, a los servicios médicos, a yivienda, a bienes materiales, son cuestiones candentes en muchas de las sociedades dernocratizadas recientemente en Latinoamérica, África y Asia. No menos importante, cuando uno piensa retrospectivamente en Solón y er el campesinado endeudado de la $\Lambda$ tica, es el peso que la deuda y la posición subordinada dentro de la división laboral internacional suponen para estas socicdades. Las condiciones 
para el funcionamiento de la democracia en el tercer mundo dependen, en buena parte, de la cancelación o reducción drástica de la deuda, así como de la transferencia de un 1 ó $2 \%$ del PIB al año de los paises industrializados al tercer mundo, a través de instituciones internacionales, etcétera. Como René Dumont sostiene:

«La brecha creciente entre los paíscs pobres y los ricos se está haciendo cada vez más y más intolerable. Si continúa aumentando podríamos, para mediados del próximo siglo, tener más de dicz mil millones de pobres en nuestro pequeño planeta, frente a mil millones de ricos. Tal situación sería isostenible políticamentes ${ }^{4}$ !.

También dentro de las sociedades occidentales, la isomoiria continúa siendo una preocupación viva. El control de quienes gozan de riquezas y privilegios sobre los medios de comunicación o sobre las campañas de recogidas de fondos para los partidos políticos en sociedades como los Estados Unidos ${ }^{42}$, no puede sino viciar el funcionamiento de la democracia. La ausencia de un sistema universal de seguro sanitario en tales sociedades o las terribles condiciones en que viven los pobres en el seno de las ciudades, son una denuncia a una politica en que los valores de mercado se han descontrolado. Tampoco son los Estados Unidos la única sociedad occidental en que existe un importante grado de desigualdad. Uno se pregunta cómo se tomaría Europa Occidental, Japón o Canadá las propuestas de John Stuart Mill, a mediados del pasado siglo, de tasar en un $80 \%$ la renta por herencia ${ }^{43}$. O hasta donde podría llevarse un impuesto sobre la riqueza del tipo propuesto, tímidamente, por el gobierno socialista francés experimentado al principio de la década de los ochenta. En un período, además, que ha sido testigo de la transferencia de renta a modo de reforma tributaria desde los estratos medio e inferior de la socicdad hasta el $20 \%$ más alto, la batalla puede que consista menos en crear nuevos puntos de partida, cuanto que en la defensa de los principios de justicia social inherentes en el Estado de bienestar. Y esta batalla, cada vez más, necesita ser librada a escala global.

Así como el capitalismo se ha ido globalizando cada vez más (los bloques comerciales regionales han ido surgiendo en Europa, Norteamérica, etc.; cl alcance de las corporaciones transnacionalcs $y$ agencias internacionales como el FMi y el Banco Mundial han demostrado su cuasi omnipresencia, etc.), también nosotros hemos de pensar en la democracia de un modo menos parroquial. Hemos de hacer en occidente algo más que congratular a nuestros (menos afortunados) compañeros de Latinoamérica, Europa del Este, sur de Asia y sudeste asiático, así como África por haber visto la luz. Hemos de reconocer la necesidad de hacer un balance entre isonomía, isegoria c isomoiria, no sólo en nuestras respectivas sociedades, sino también internacionalmente.

En lo que se refiere a isonomía, un logro fundamental sería extender las protecciones subrayadas en códigos tales como la Declaración Universal de Derechos Humanos a todos los habitantes del plancta. Hasta cierto punto, la presión exterior en torno a los derechos humanos contribuyó a la liberalización y posterior democratización de las sociedades de Europa del Este y de Latinoamérica. Cuando los derechos humanos comiencen a gozar de mejores puestos en la política exterior de los países desarrollados que los que tienen los derechos de inversión, cuando los préstamos y la ayuda de parte de esas agencias internacionales se unan a una visible mejora cn el balance de derechos humanos de los estados receptores, entonces comenzaremos a ver el eclipse de la tiranía y la dictadura como formas políticas prevalecientes. 
Intimamente relacionados con las libertades formales de opinión, religión o elección política están los derechos sociales. También aquí documentos de las Naciones Unidas como la Declaración sobre el Progreso Social y el Desarrollo adoptada por la Asamblea General en 1969, contribuyen a mostrar el camino a seguir, aunque más importante será el grado de compromiso que los pueblos y los gobiemos del mundo den a una medida de isomoiría en todo el planeta. No estoy hablando de un balance radical de la riqueza, ni de una erradicación absoluta de las diferencias verdaderamente reales de los standards de vida medidos por el PIB per cápia, los porcentajes de mortalidad, el acceso a la educación, la salud, etc., que distinga a los ciudadanos de países centrales de aquellos de la periferia en nuestros dias. Las diferencias estructurales dificilmente desaparecerán, si bien el porcentaje de esas diferencias puede reducirse en el tiempo. Un compromiso hacia cierta versión básica de seguro sanitario, educación, comida y vivienda para todos los habitantes del globo terráqueo no parece un objetivo imposible en un periodo en el que la tensión internacional, al menos del tipo de la Guerra Fría, está en declive. ¿Puede la voluntad moral y política que está a punto de realizar csto ser destruida?

En cuanto a la isegoria, difícilmente podemos escapar a las estructuras de nación-Estado en las que vivimos o cuestionar en su totalidad a las instituciones políticas representativas que someten al mutismo a la participación ciudadana. Sin embargo, así como existen ejemplos de participaciôn directa dentro de las naciones-estado, también se dan en la arena internacional. Organizaciones no gubernamentales como Amnistía Internacional, Greenpeace, Oxfarn y muchas otras, han jugado un papel fundamental haciendo avanzar la solidaridad internacional, confiriendo también en cientos de miles de personas en el mundo la idea de que la participación a escala global no es una imposibilidad. Estamos aún a años luz de alcanzar instituciones representativas que posean un poder unificador a través de los continentes, dejando aparte la democracia directa del tipo de referendos. Aun así, cn una época de comunicaciones globales y de transmisiones instantáneas de información, no deberíamos subestimar las posibilidades de la participación política que puedan surgir.

Quiero concluir con una nota realista. La propia Atenas, el primer modelo en funcionamiento de democracia, tal y como la conocemos, duró más de dos siglos. Sin cmbargo, la isonomía fallo por la exclusion de una gran mayoría de la población en la categoría de ciudadanos; su isegoría no significaba que grandes líderes como Pericles, Cimón o Demóstenes no ejercieran una infuencia desproporcionada sobre la asamblea, en comparación con los ciudadanos corrientes; en cuanto a la isomoiria, era más una aspiración de algunos, que una realidad viva en los siglos VI, v y IV a.C. En el Mundo modemo, las democracias liberales de Norteamérica o Europa occidental tienen uno o dos siglos. También ellas excluyeron durante mucho tiempo grandes grupos de población (los negros y las mujeres, por ejemplo) de la ciudadanía; la participación ciudadana ha sido más episódica e infrecuente que en Atenas, y a pesar de modestos avances en lo que refiere al estado de bienestar y a una política tributaria progresista, estos logros no excluyen los rasgos desigualitarios de la economía de mercado.

Postular la isonomía, isegoría e isomoiria a escala global, por consiguiente, podría parecer un espejismo, tanto más cuanto que la democracia está aún siendo puesta a prueba en las políticas post-autoritarias de Latinoamérica, la Europa del Este, así como ausente del todo en partes de África y Asia. Por otra parte, podríamos estar 
haciendolo peor que intentando anticipar modelos de democracia un siglo o dos en el futuro. Una teoría que incorpora los tres conceptos griegos que he estado subrayando a lo largo de este ensayo, nominalmente, dercchos de ciudadanía iguales, la oportunidad igual de participación política, y una medida de igualdad económica y social, pueden asegurar que la democracia, 2.500 años después de su comienzo, retendrá todo su atractivo normativo.

\section{NOTAS}

1 Rohert Dahl, Domocracy and its Critios (New Haven: Yale University Press, 1989), p. 333.

* Parte de la literatura más relevante acerca de esta transfotmación incluiria la siguicnte: Fornando Carduso, "Democracy in Lalin America", en Politics and Socter, 15, 1946, pp. 23-41: Elections and Democratization in Latim America, Paul Drake y Eduardo Silva, editores (San Diego: University of Calilornia, 1986); Thansitions from Authortarian Rule, $G$. O'Donnell, P. Schmitter y L. Whitehead, editores (Baltimme: John Hopkins University Press. 1986); Democatizing Brazii. Alfred Stepan, ed. (Nuevai York: Oxtord University Press, 1989); asi como da parole et le sang: poltlique of secété con Amćrique latine, de Alain Touraine (Paris: Editions Odile Jacob, 1988 ).

"Literatura relevante acerea de este fenómemo en la Union Sovietica y demas paises del Esto podria incluir los siguientes trabajos: The Uses of Adtersity, de Timothy Gitron Ash (Londres: Granta Bikoks, 1989); Archic Brown. "Political Change in Soviet Unionm, en Forki Policy loumal, 1989, pp. 469511; Stephen Cohen y Katrina Vanden Hatisen. editores. Walces of Glannost: Inteniews with Gomachev's Reformess (Nucva York: Norton, 1989); Mikhail Corbachev. Peresiroika: New Thinking for Our Cownty and he Wonl (Nueva York: Harper and Row, 1987); Vaclay Havel, liwing in Thut (Londres: Faber \& Faber, 1989); Banch IItzan, Combariev's Camble: The 19h All-Union Pary Conference (Goulder: Westvicw, 1900): Gatl Lapides, *State and Socicty: Toward the Fmergence of Civil Society in the Soviet Union", on Politics, Society and Saconi Sorialist Rewolution, Seweryn Bialer, ed. (Boulder: Wostview, 1000); y, finamente, fa obra de Tanya Caslawskays, The Second Sociolist Revolution (Londres: I. B. Tauris, 1990).

* Acerca de los regimenes marxista-leninista, uno de los análisis más inteligentes continúa sicndo el de F. Fëhur. A. Hellery G. Markus, Diciatorship oner Needs (Oxford: Basil Blackwell, 1983).

* Muchos de los trabajadores en ciencia politica del período posterior a la Segunda Guerra Mundial, especialmente en los Estadus Unidos discuten tal posicion. Algunos ejemplos incluirán los siguientes trabajos: G. A Almunt y S Verba, The Cint Culture (Boston: Littlc Brown, 1965); B. R. Bertson, P. F. Lazerfeld y W. N. McPhee, Voring (Chicago: University of Chicago Press. 1954); Robut A. Dalle, A Prefote to Demo- cratic Theory (Chicage: University of Chicago Press, 1956); y, finalmente, S. M. Lipset, Potitical Man (Nueva York: Double Day, 1963).

- M. Cruzier, S. P. Huntington y J. Watankki, The Crisis of Denocracy: Report on the Governabiy of Democractes to the Triateral Commission (Nueva York: 1975).

7 Me refiero a trabajos tales como Capitalsm and Freedom de Milton Friedman (Chicago: Univerwity of Chicago Press, 1962); Friedrich A. Hayck, 7he Conssitution of Liberty (Chicage: University of Chicago Press, 1960): y James M. Buchanan, Libery. Market and Stat' (Wheatsheaf Books, 1986).

" Cr. Jon Roper. Demacracy and its Critis: Anglo-Anerican Democratic Though in the Nineteenth Centuy (Londres: Unwin Hyman, 1989).

"C. Wright Mills, he Power Llite (Nueva York: Oxford University Press, 1956).

- Algunos ejemplos podrian incluir algumos de Ios escritoras an cl libro Franters of Dewacratio Theory. Henry S. Kariel, ed. (Nueva York: Random House. 1970), Parte 111; Carole Pateman, Particigation ant Democmtic Theory (Cumbridge: Cambridge Univerwity Press, 1970; C. B. Macpherson. The Lffe and Times of litheral Demoency (Oxford: Oxford University Press. 1977), Jane Mansbridge, Beymd Adverwy Demecraty (Nueva York, 1980); Benjamin Barber, Strong Demoarcy: Participatory Politics for a Now Age (Berkeley: University of California Press, 1984); asi como ef trabajo de Philip Resnick Itarlament ws. Poople: An Essay on Demornay and Cantulitan Political Culuers. (Vancouver: New Star Books, 1984)

is Norberto Bobhin, Riberalism and Demecracy (Londres: Verso, 1990), p. 43,

12 Benjamin Constant, "The Liberty of the Ancients compared with that of the Moderns», en Political Writings, Biancamaria Fontana, ed. (Cambridge: Cambridge Universicy Press, 1988).

${ }^{3}$ David Stucklon, The Classical Athenian Democrary (Oxford: Oxford University Press, 1900). p. I.

1" Thid. Para una discusión anterior de los tres téminos que figuran en el titulo de exte trabajo, ver al capitulo l." de mi libro The Mask of Proteus: Canadian Reflections on the State (Montreal: McGill-Queen's Universicy Press, 1990), especialmente las pp. $30-31$.

15 Cfr. J. D. Lewis, "lsegoria at Athens: When Did It Begin? ${ }_{2}$, Iistorice, 20, 1971, pp. 129-140. 
in Hay una breve discusión del tórmino ismmiria en el ensayo de Claude Massé "Egalité», en La démocratie grecque (Paris: MA Editions, 1986). Para una vision más negativa de isomolria ver la obra de Donald Kagan, Pericles of Ahens and the Birth of Democracy (Nueva York: The Free Press, 1991), pp. 62 y 272 . Ver tambien la ohra de Christian Maicr, The Sreek Discovery of Politics (Cambridge: Harvard University Press. 1990), cap. 3

"Citado en Aristóteles, Constitution of Athers, 12, en Democracy: Ideas and Realites, Cosmo Rodewald, ed. (I.ondres: J. M. Dent, 1974), p. 59.

1* sEl verdadero fundanento de la diferencia entre la oligarquía y la democracia es la pobreza y ha riqueza. Es evidente que cualquiter constitución haya de ser una oligarquía si los gobernuntes que gebiemen bajo ella son gobernantes en virtud de la riqueza, tanto si son unos poes como muchos; y es igualmente inevitable que una constitución bajo la cual gobiernan los pobres haya de ser una democracia.s Aristóteles. foitics, Libro III, rad. (al inglés) por Enest Barker (Oxford: Oxford University Press, 1948, , p. 134.

${ }^{19}$ Soviet Demochy in the Era of Developed Socia lism (Moscow: Progtess Publishers, 1979), pp. 12, 13, 16-17.

29 Zaslavskaya. The Second Socialist Revolution. pp. $15,4546,115$.

2) Stockton, Classical Athenian Democracy. pp. $21-28$

: Como Giowanni Sartori ha sostenido cotrectamente: «No gobicrno del pueblo, ya que d puehlo no sabe lo bastante como para reconocer sus verdaderos intereses; sino gobierno sobre el pueblo, a pesar del mismo pucblo, en el interés dol pueblo. Extâ es la justificacion standard de todas las tiranias.s. The Theory of Democray Revisited (New Jersey: Chatam House Publishers, 1987), p. 475.

${ }^{3}$ Cf. M. 1. Finley. Folitics in the Ancient World (Cambridge: Cambridge University Press, 1983), capitulo 4.: Victor Ehrenberg, The Graek Siate (Londres: Menthuen, 1969), pp. 52-74; Morgens Herman Hansen, The Athenian Assembly in the Age of Demosthenes (Oxford: Basil Blackwell, 1987); Josiah Ober, Mass and Elite in Democratic Athens (Princeton, Princeton University Press, 1990 ).

* Kanl Marx, Gundisse, en el libro de David Mclelland, ed. Kan Maxx: Setected Writings (Oxford: Oxfond University Press, 1977), p. 360 .

25 James Madison, The Federolits Papess, wol X; Joseph Shumpeter, Capialism. Sociatism and Democracy (Nucva York: Harper \& Bros., 1942), parte IV.

2t Cf. los referendos italianos o suizos, en donde un pequeño porcentaje de firmas de ciudadanos es suficiente para someter una cuestión al electoraro. C.t. tambićn la práclica en varios Fstados de los Estatos Unidos de América, como lo discute Thomas E Cronin en Ditect Democracy: The Poltics of Inciative, Referendum, and Recall (Boston: Harvard University Press, 1989).
* Cf, Ican Buthke Elshtain, Public Man, Prwate Woman: Women in Social and Political Thought (Princeton: Princeton University Press, 1981); Carole Pateman y Elizabeth Gross, Fominist Chatlenges: Social and Politicat Theory (Londres: Allen \& Unwin, 1986).

3v $\mathrm{Cr}$. Robert C. Pachlke, Environmentalism and the Future of Progressive Politics (New Haven: Yalc University Press. 1989); Barry Commoner, Making Peace With the Planer (Nueva York: Panthen, 1990); Boyce Richardson, Time to Change (Toronto: Summerhill Press, 1990).

2. "No decimos que un hombre que no tient inlerés en política es un hombre que se meta sólo en sus propios asurtos; lo que decimos es que et no ticne aqui asuntos de ningún tipow. Oración Fúnebre de Pericles en Tueidides, History of the Proponnesian War, traducido (al inglés) por Rex Warner (Peguin Books, $1954)$, p. 147.

* Cf Nancy Rasenblum, ed, Libaralism and the Mord Life (Cambridge: Harvard University Press, 1989): Alasdair MacIntyre, After Virtue (Notre Dame: University of Notre Dame Press, 1981); Charles Taylor, Philosophical Papers, II (Cambridge: Cambridge University Press, 1985).

"Cf. Constant, aThe Liberty of the Ancicuts compared with that of the Moderns", ob. cit.

$\because$ Cf. la discusión del tenómeno jacobino en el libro de Ferenc Feher, The Frozen Revolution: An Essay on Jacobinism (Canbridge: Cambridge University Press, 1987). Ver también de Stanislaw Ehrfich ePluralism and Marxism», cn Three Faces of Maxim, $\mathrm{S}$. Eturlich y G. Wootton, ed. (AIdershot: Gower, 1980), especialmente la seccion oIn What Sense Were Mars, Engels and the Bolsheviks Jacobins:"n, asi como $\mathrm{mi}$ artículo «La democratic dirccte peut-cle cockister avec l'etat moderne?, en Les formes modemes de la démocratie, Gerard Boismenu, ed. (Montreal: Presses de L'Université de Montréal, 1992).

$\therefore$ Cf. Kagin, Pericles, pp. 62 y 270.

${ }^{3}$ Ober, Mass and Elite in Democratic Athens, ob. cit., p. 202. Aunque está medida se aprobó en la aæamblea, nunca se adoptó.

is Ibid, 337.

*: Andrew Shonfield, Modem Capitalsm: The Changing Butance of Public and Prwate Power (Oxford: Oxford University Press, 1965).

is * stagflation es un vocablo resultante de la uniŏn de dos términos en ingles, nominamente, stagnation (estancamiento) e inflution (inflación). para el cual no hay equivalente en castellano. (N. del T.)

33 Cf. Keith Joseph y K. Sumpton. Eathitin (Londres: J. Muray, 1970); Samuel Brittan, The Econontic Conseguences of Democracy (Londres: Temple Smith, 1977) y la ohra de James M. Buchanan y Richard F. Wagner, Democtasy in Defict: The Pofitical Legacy of Lord Keynes (Nucva York: Acadenic Press, 1977). para ver algunos argumentos representativos. Para un andilisis crítico del giro neo-conservador ver, entro otrus, F. F. Piven y R. A. Gloward, The Now Chas War 
(Nucva York: Panthcon, 1985); Ramesh Mishra, The Welfare State in Capitalist Society (Toronto: University of Toronto Press, 1990).

*itado en el articulo de Adam Przcworski, «Some Problems in the Study of Transition to Denocracy, en G. O'Donnell, et al. Transitions from Authoritarian Rute, ob. cit., p. 63 . th Zaslawskaya, Second Socialist Revolution, oh. cit., p. 131 .

4) René Dumont, Démocratie pour LAfrique (Pa. ris: Seuil, 1991), p. 9. La traducción es mir.

${ }^{42}$ Michacl Parenti, Democracy for the Few (Nueva York: St. Martin's Press, 1980), 3. ta edición.

4. John Stuart Mill, Principles of Political EConomy, 7.4 edición (1871), Labro II, cap. 2.

\title{
A propósito de Holzwege
}

\author{
ARTURO LEYTE COELLO
}

Universidad de Vigo

Holzwege es el título que propuso Heidegger para una obra publicada en cl año $1950^{2}$. Como ocurre con muchos de sus libros, estc recoge diversos materiales escritos cuya procedencia data de los años que van de 1935 a 1946 . No hay por lo tanto tal libro cerrado, sino un título bajo el que se recoge un trayecto.

Holzwege, traducido al castellano ${ }^{3}$ y publicado en Argentina en 1960, gozó en nucstro medio cultural de una singular buena suerte. Tal vez se trate de la obra más leída de Heidegger en España, por encima incluso de Ser y tiempo. No es inverosimil que causa de esta suerte sca el título con el que se tradujo e introdujo la obra en Ios paises de habla española. En efecto, el sugestivo título de «Sendas perdidas» no fue en última instancia un mal reclamo para una obra que, juzgada desde la perspectiva del conjunto de la obra de Heidegger, tanto por la época cuanto por el contenido de cada uno de los ensayos, es de Io más compleja. El titulo, un acierto desde la perspectiva editorial, a pesar de no ser completamente acertado, configuró todo un modo de lectura de Hcidegger. En cierto modo, la sugestión y evocación del título condicionó de alguna manera la lectura de la obra, relegando los aspectos más duros de la misma: las dificultades deI griego quedan veladas por la evocación de los pasajes donde la lengua gricga hace su presencia; la compleja disquisición sobre el arte queda disminuida por la sencilla referencia a un cuadro de Van Gogh, de la misma manera que la extraña y difícil reflexión sobre el lenguaje y la poesia parece digerirse por medio de una poesía de Rilke, sin percibir por cierto a su vez la intrínseca dificultad de ese poema; el ensayo sobre Hegel, quizás uno de los de mayor dificultad técnica, parece más tratable en cuanto se fija la atención en esa dinámica lectura de la conciencia como lucha; el conocimiento profundo de la historia de la filosofía que presupone el ensayo sobre Nietzsche parece obviarse gracias a la sintética y aparentemente reduccionista comprensión de la filosofía de Nietzsche como metafísica; en fin, el ensayo sobre la modernidad - «La época de la imagen del mundo*- parece a su vez despistar de su auténtica dificultad gracias al carácter de diagnóstico que ofrece en su primera página, que lo convierte en una suerto de fácil 